\title{
Intravenous Injection of an Adenovirus Encoding Hepatocyte Growth Factor Results in Liver Growth and Has a Protective Effect Against Apoptosis
}

\author{
Daniel Phaneuf, Shu-Jen Chen, and James M. Wilson \\ Institute for Human Gene Therapy and Departments of Molecular and Cellular \\ Engineering and Medicine, University of Pennsylvania and Wistar Institute, \\ Philadelphia, Pennsylvania, U.S.A. \\ Communicated by J.M. Wilson, Accepted December 14, 1999.
}

\begin{abstract}
Background: Hepatocyte growth factor/scatter factor (HGF/SF) is a pleiotropic cytokine with mitogenic, motogenic and morphogenic effects for a wide variety of cells. Previous studies have reported that the in vivo infusion in normal, untreated mice of recombinant HGF results in low levels of DNA synthesis and liver proliferation. In this study, we examined whether liver regeneration could be obtained by the in vivo injection of a recombinant adenoviral vector encoding human HGF (Ad.CMV.rhHGF) in normal, intact mice. Materials and Methods: C57BL/6 mice were infused intravenously with doses increasing from 1 to $4 \times$ $10^{11}$ particles of the recombinant human HGF (rhHGF) adenoviral vector or with a control virus encoding Escherichia coli $\beta$-galactosidase (Ad.CMV.lacZ). At day 5, mice were sacrificed and evaluated for the presence of hepatocyte mitogenesis and liver regeneration (5-bromo-2'-deoxyuridine (BrdU) assays and liver weight determination) and for the presence of liver damage (serum alanine amino-transferase (ALT) measurements and TUNEL assays).
\end{abstract}

Results: In vivo administration of rhHGF stimulated DNA synthesis of hepatocytes and liver weight in a dose-dependent fashion. The maximal effect was seen after the infusion of $3 \times 10^{11}$ particles which resulted at day 5 in $>130 \%$ increase in relative liver mass with little cytopathic effect. In contrast, administration of the lacZ adenoviral vector caused little hepatocyte replication, but induced high levels of serum ALT ( $\sim 3$ times higher than the rhHGF vector) and significant apoptotic cell death.

Conclusions: This study shows that a single injection of Ad.CMV.rhHGF alone is able to induce in vivo and in a very short period of time, robust DNA synthesis and liver proliferation in normal mice without liver injury or partial hepatectomy. This recombinant adenoviral vector has a lower toxicity than the control lac $Z$ adenovirus. This suggests that HGF may have a protective effect against adenovirus-induced pathology.

\section{Introduction}

Hepatocyte growth factor (HGF), also known as scatter factor (SF), is a multifunctional polypeptide with actions on a wide variety of cells (1). HGF/SF can stimulate DNA synthesis, cell migration and morphogenesis in a variety of epithelial cells types in culture, including Madin-Darby canine kidney (MDCK) cells (2) and A549 human lung carcinoma cells (3). HGF was first purified from rat platelets as a

Address correspondence and reprint requests to: Dr. James M. Wilson, Institute for Human Gene Therapy, University of Pennsylvania Medical Center, Room 204, The Wistar Institute, 3601 Spruce Street, Philadelphia, PA 19104-4268; Phone: 215-898-1979; Fax: 215-898-6588; Email: wilsonjm@mail.med.upenn.edu potent mitogen for mature hepatocytes (4). In vivo, HGF is involved in cellular functions such as wound repair, organ development and regeneration (5). The level of HGF in the liver and serum increases markedly and rapidly after various injuries, like partial hepatectomy or experimentally induced hepatitis, by the administration of hepatotoxins such as carbon tetrachloride or D-galactosamine (6-8). The cloning and sequencing of cDNAs from humans $(9,10)$, rat $(11,12)$ and mouse $(13)$ reveals that HGF consists of a heterodimer synthesized in a single polypetide chain of 728 amino acids composed of an $\alpha$-subunit of $69 \mathrm{kD}$, which contains four Kringle domains and a $\beta$-subunit of $34 \mathrm{kD}$. More than $90 \%$ of homology exists in 
the primary structure of HGF among these three species (13).

The mitogenic property of HGF was demonstrated clearly in vitro or in animals after liver injury (4). However, the stimulation of hepatocyte replication in intact animals, in the absence of liver injury, was achieved only by an invasive $24 \mathrm{hr}$ or $5 \mathrm{~d}$ continuous intraportal infusion of human HGF in mice $(14,15)$. In this study, we demonstrate that hepatocyte replication can be achieved in animals by the administration of an adenoviral vector encoding human HGF, without the need for liver injury.

\section{Materials and Methods}

\section{Adenoviral Vectors}

The El-deleted recombinant adenoviral vector, Ad.CMV.rhHGF, expressing HGF under the transcriptional control of the cytomegalovirus (CMV) immediate early enhancer/promoter was constructed by inserting the $2.3 \mathrm{~kb}$ human HGF cDNA into the plasmid pAd.CMV-Link.1. This construct was cotransfected with sub360 purified DNA into 293 cells (American Type Culture Collection (ATCC), Rockville, MD) as described (16). Positive plaques were picked up and further purified by three other rounds of plaque purification. The recombinant adenoviral vector, Ad.CMV.lacZ, containing the Escherichia coli $\beta$-galactosidase in the El region was described elsewhere (17).

\section{Evaluation of HGF Activity}

To evaluate HGF activity, recombinant human (rh)HGF was tested for its ability to scatter human lung carcinoma A549 cells (ATCC). Confluent dishes of A549 cells were seeded with the supernatant of 293 cells infected with Ad.CMV.rhHGF. Cells were incubated for $24 \mathrm{hr}$ and the scattering effect was monitored by light microscopy.

\section{In vivo Delivery of Recombinant Adenoviruses} to the Mouse Liver

All mice were housed in a pathogen-free facility, maintained on a $12 \mathrm{hr}$ light/dark cycle and fed ad libitum with a standard rodent chow (Pico-Vac Lab Mouse Diet, Purina Mills, Inc., St. Louis, MO). Six- to eight-week-old C57BL/6 mice were weighed and intravenously injected via the tail vein with 1 to $4 \times$
$10^{11}$ particles of one or a predetermined combination of both recombinant adenoviruses (Ad.CMV.lacZ, or/and Ad.CMV. rhHGF) in 100 $\mathrm{ml}$ of phosphate-buffered saline. Necropsies were performed $5 \mathrm{~d}$ later.

\section{Immunohistochemistry Analyses}

Mice were intraperitoneally injected with $250 \mu \mathrm{l}$ of an aqueous solution of 5-bromo-2'deoxyuridine (BrdU, 3 mg/ml, Amersham Pharmacia, Biotech Inc., Piscataway, NJ) to monitor DNA synthesis. Animals were sacrificed after 1 $\mathrm{hr}$ and livers were weighed and quickly frozen in liquid nitrogen. Fixed and paraffin-embedded liver sections were probed with a monoclonal antibody to BrdU conjugated with alkaline phosphatase, as described by the supplier (Roche Molecular Biochemicals, Indianapolis, IN). The concentration of human HGF in the serum of mice injected with Ad.CMV.rhHGF was determined by the enzyme-linked antigenspecific antibody assay (ELISA, R\&D Systems, Minneapolis, MN). Apoptotic cells were recognized in tissue sections from mouse liver by using the Tat-mediated dUTP-Xnick-end labeling (TUNEL) method (in situ cell death detection kit, Roche Molecular Biochemicals). The incorporation of fluorescein-dUTP was detected microscopically.

\section{Liver Function Tests}

Serum alanine amino-transferase (ALT) and serum aspartate amino-transferase (AST) assays were performed on serum collected from mice.

\section{Results}

The E1/E3-deleted adenoviral vector, Ad.CMV. rhHGF, contains the human recombinant cDNA encoding hepatocyte growth factor (HGF) driven by the cytomegalovirus early promoter/ enhancer (CMV). HGF possesses a wide range of biological activity on a variety of cells, including mitogenesis (hepatocyte replication), motogenesis (scatter factor) and morphogenesis (1). To verify that the recombinant HGF produced by Ad.CMV.rhHGF is functional, its scattering activity was assayed in vitro on the epithelial A549 lung carcinoma cell line. Confluent dishes of A549 cells were seeded in conditioned media from Ad.CMV.rhHGF-infected 293 cells. The scattering effect, seen as signifi- 

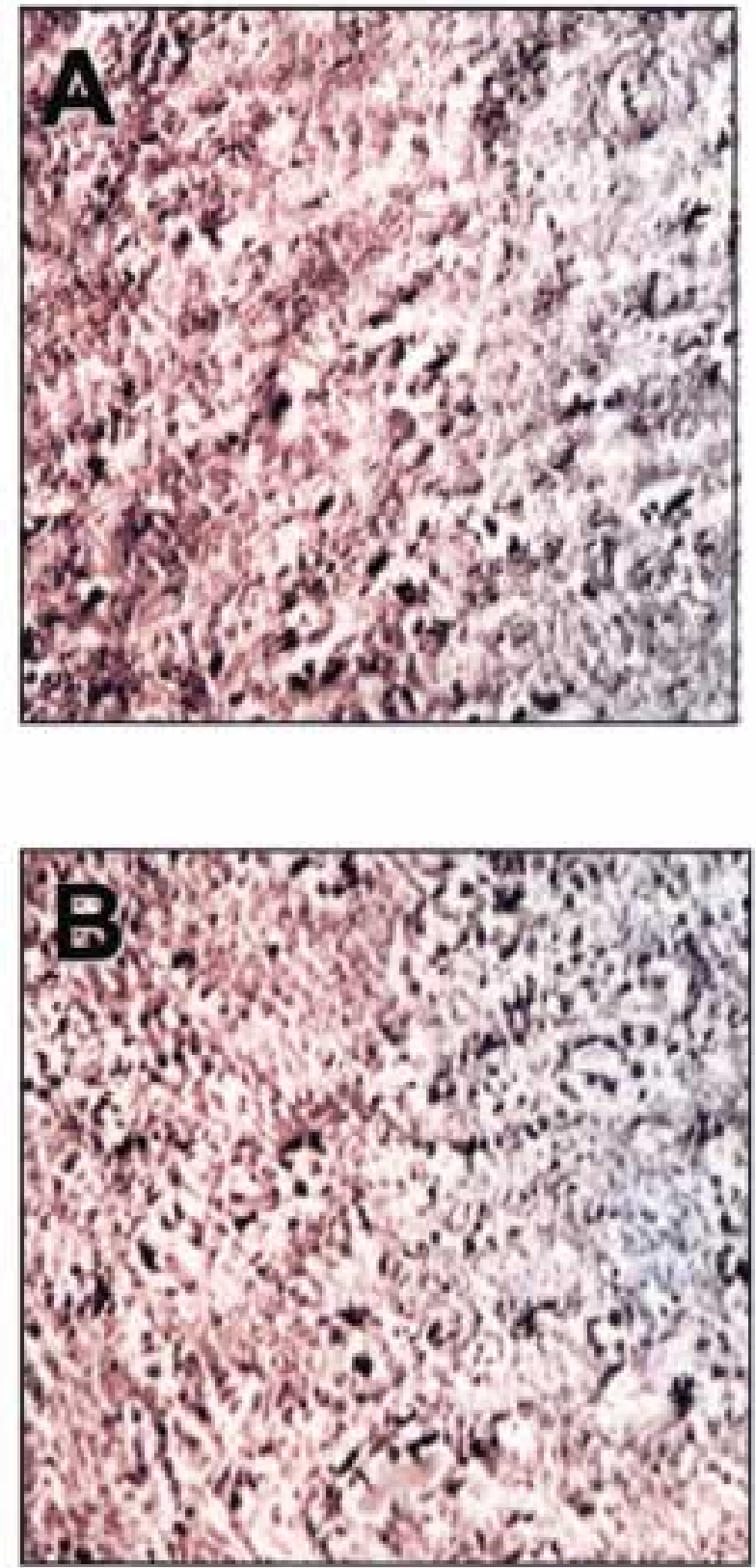

cant cell separation at the light-microscopic level, was detectable after $16 \mathrm{hr}$ of incubation (illustrated in Fig. 1). Conditioned media prepared from the supernatant of 293 cells infected with a control adenoviral vector expressing E.coli $\beta$-galactosidase (Ad.CMV.lacZ) had no detectable scattering activity (Fig. 1B).

To determine if rhHGF alone could initiate hepatocyte replication and liver growth in the absence of liver injury (partial hepatectomy or a hepatotoxin), normal and intact mice were tail vein-injected with 1 to $4 \times 10^{11}$ particles of the rhHGF or lacZ adenoviral vector. Five days later, mice were injected intraperitoneally with

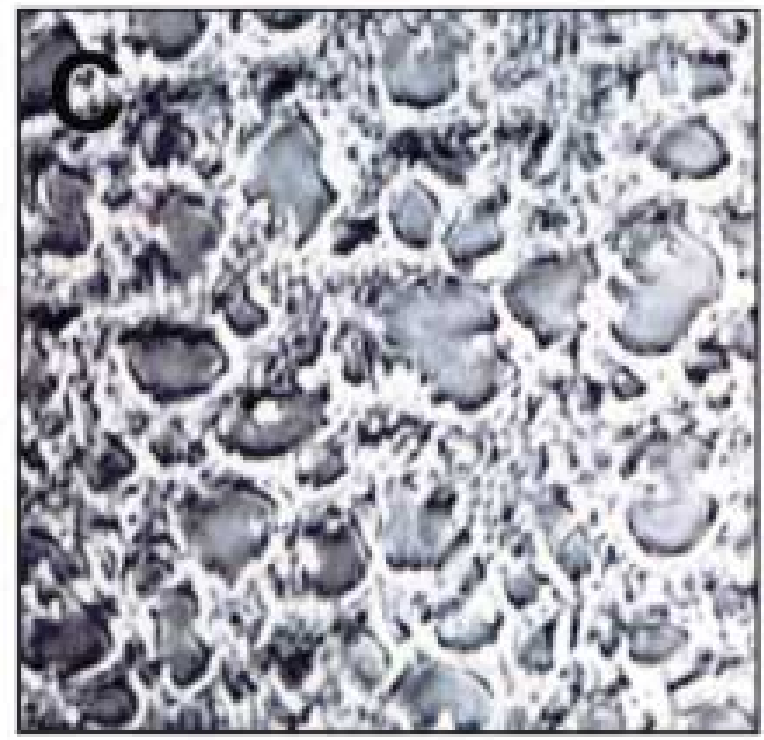

Fig. 1. Scatter factor assay on A549 cells. Cells were seeded with media from (A) non-infected cells, (B) Ad.CMV.lacZ- or (C) Ad.CMV.rhHGF-infected 293 cells and incubated for $16 \mathrm{hr}$ at $37^{\circ} \mathrm{C}$. The scattering effect was monitored by light microscopy.

BrdU, a thymidine analog that is incorporated only into actively dividing cells. Livers and sera were harvested one hr later to determine the efficiency of gene transfer and to study hepatocyte replication.

To determine the efficiency of gene transfer, the rhHGF level in the blood of mice injected with Ad.CMV.rhHGF or Ad.CMV.lacZ was determined at the time of sacrifice (day 5) by ELISA, using anti-human HGF antibodies. Serum rhHGF levels detected in mice intravenously injected with 1 to $4 \times 10^{11}$ particles of the rhHGF adenoviral vector ranged from 5.5 to $>8.0 \mathrm{ng} / \mathrm{ml}$ (data not shown). No HGF was detected in mice intra- 
venously injected with 1 to $4 \times 10^{11}$ particles of the lac $Z$ adenoviral vector.

The two parameters studied to determine the effect of rhHGF on hepatocyte replication were liver weight and DNA synthesis. The weight of the remnant liver and the entire animal was measured at the time of sacrifice (day 5) and expressed as a ratio (liver/body weight $=$ weight ratio) to take into account the difference in the body weight of each animal. At low doses $\left(10^{11}\right.$ particles), no difference was observed in the weight ratio between the laczand the rhHGF-injected mice (Fig. 2). However, the weight ratio increased gradually as a function of the number of particles of Ad.CMV.rhHGF injected ( $\Delta$ ratio from 1 to $4 \times 10^{11}$ particles injected $=0.032$ ). The maximal effect was seen after the infusion of $3 \times$ $10^{11}$ particles, which resulted at day 5 in $>130 \%$ increase in relative liver mass. In contrast, little difference was observed in the weight ratio after injection with the control lacZ adenovirus ( $\Delta$ ratio from 1 to $4 \times 10^{11}$ particles injected $=0.009$ ). This hepatomegaly is consistent with the observed mitogenic activity of rhHGF as shown by the BrdU incorporation analysis (Fig. 3 demonstrates representative examples of BrdU staining). Control mice that received Ad.CMV.lacZ had very few replicating cells (Fig. 3). Based on these data, we conclude that infusion of Ad.CMV.rhHGF alone is able

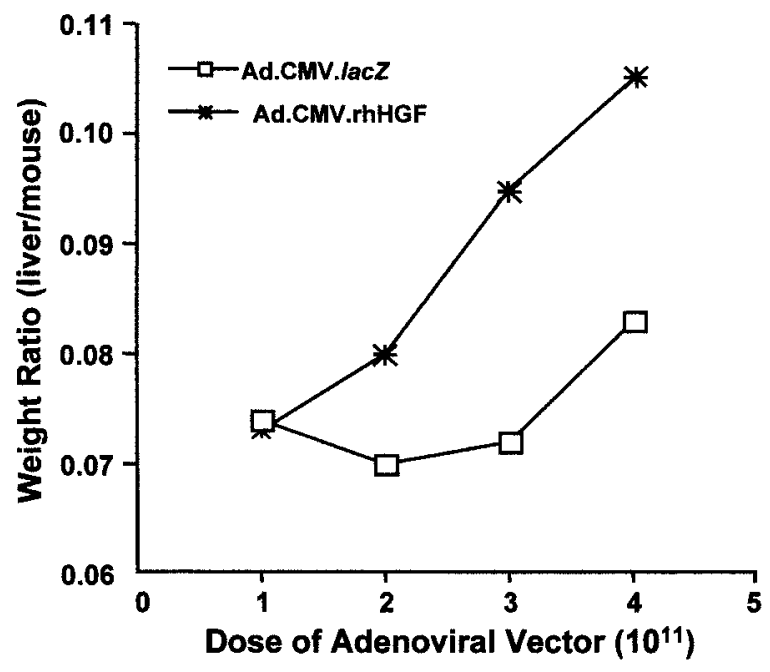

Fig. 2. Weight ratio (liver/mouse) vs. the dose of adenoviral vector administered. Animals were sacrificed $5 \mathrm{~d}$ after the administration of adenovirus and weighed prior to necropsy. The weight of the complete liver was determined before proceeding to the histoimmunochemistry analyses. to stimulate in vivo DNA synthesis, hepatocyte proliferation and, consequently, liver hypertrophy in normal mice without liver injury or partial hepatectomy.

A certain level of toxicity, largely confined to the liver, was associated with adenoviral vectors injected into the peripheral circulation (18). It was characterized mainly by neutrophilic infiltration, apoptotic degeneration of

\section{Ad.CMV.rhHGF Ad.CMV.lacZ}

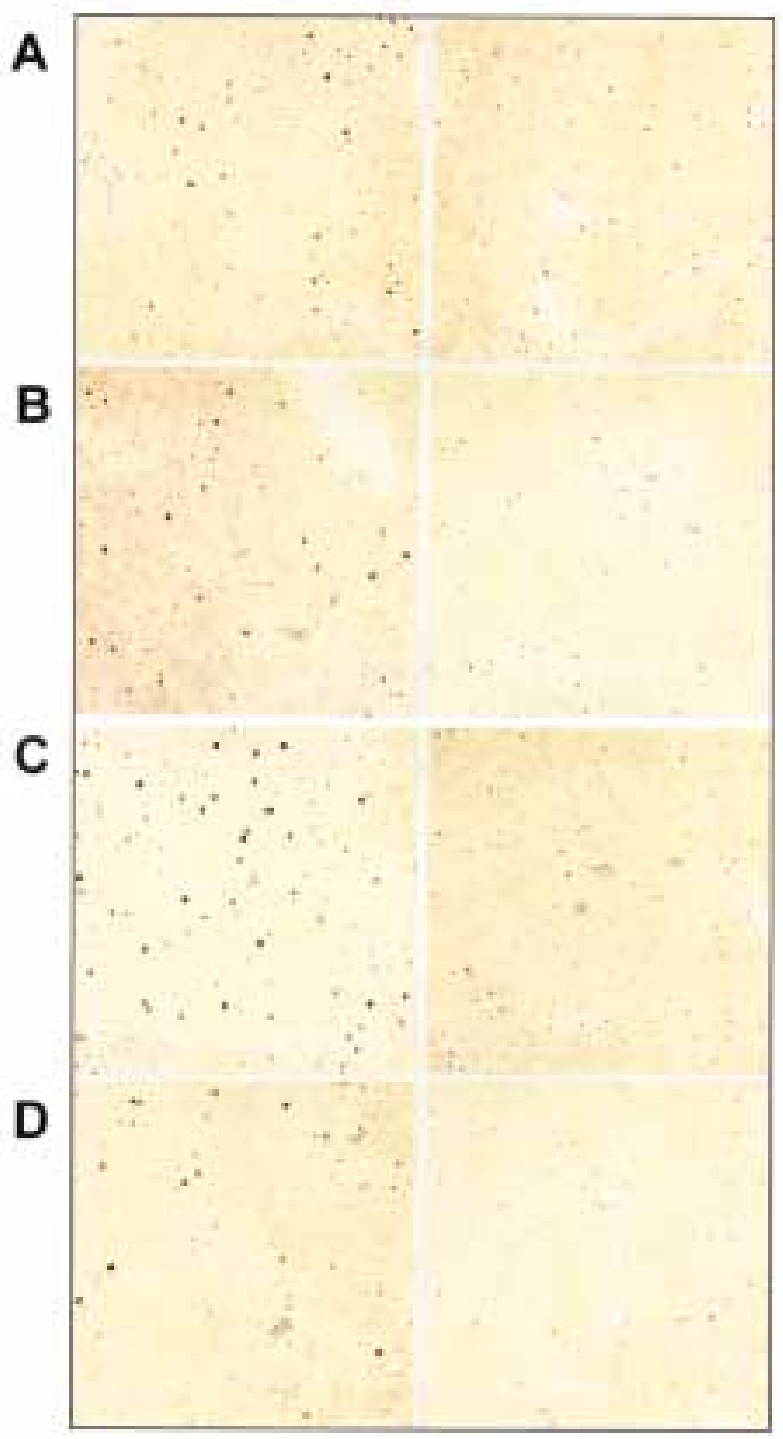

Fig. 3. Representative BrdU assays. Mice injected with (A) $1 \times 10^{11}$, (B) $2 \times 10^{11}$, (C) $3 \times$ $10^{11}$, or (D) $4 \times 10^{11}$ particles of Ad.CMV.rhHGF or Ad.CMV.lacZ were intra-peritoneally injected with an aqueous solution of BrdU and sacrificed $1 \mathrm{hr}$ later. Fixed and paraffin-embedded liver sections were probed with a monoclonal antibody to BrdU conjugated with alkaline phosphatase. Stained liver sections were analyzed at the lightmicroscopic level. 
hepatocytes and was associated with an increase in liver transaminase in the serum $(19,20)$. Animals in this study were, therefore, evaluated for pathological evidence of hepatotoxicity. Serum ALT levels in mice injected with increasing doses of the two adenoviral vectors were compared and the results of this analysis are shown in Fig. 4. Serum ALT levels in mice injected with Ad.CMV.rhHGF were on average three times lower than those of mice injected with the control (lacZ) adenoviral vector. Consistent with these results, direct examination of portions of livers from Ad.CMV. rhHGF-injected mice that were paraffinembedded, sectioned and stained with hematoxylin and eosin revealed little evidence of histopathology when compared with mice infused with the control adenovirus (data not shown). A similar experiment was performed by injecting a total of $4 \times 10^{11}$ particles of both viruses (Ad.CMV.rhHGF and Ad.CMV.lacZ) at different ratios, as shown in Fig. 5. AST and ALT levels revealed that the administration of increasing amounts of the lacZ adenoviral vector was associated with liver toxicity.

As shown in Fig. 6, TUNEL staining revealed that treatment of mice with Ad.CMV.lacz induced apoptotic cell death in the liver, while infusion of the rhHGF adenoviral vector resulted in very little cell death. The number of apoptotic cells significantly increased after the infusion, starting at a dose of $3 \times 10^{11}$ particles of Ad.CMV.lacZ (Fig. 6C). Taken together, these

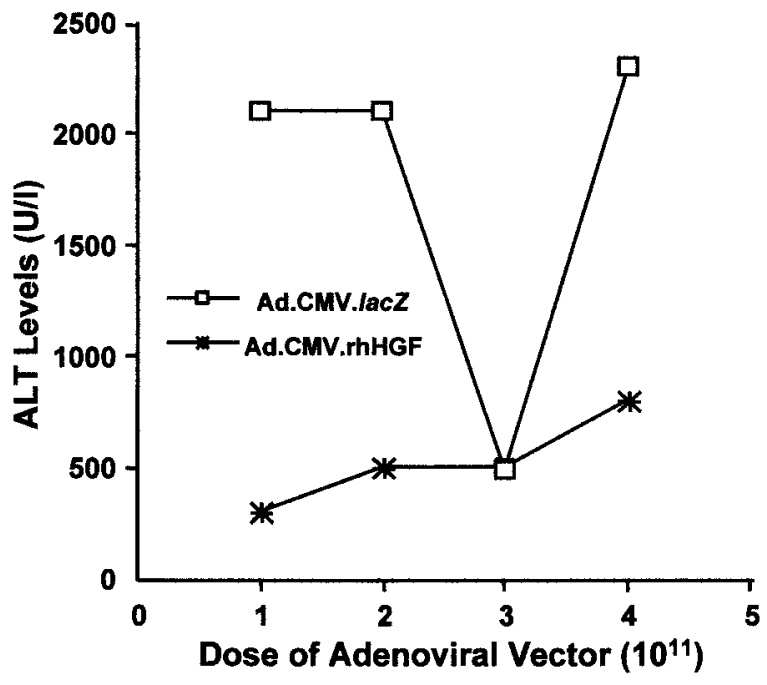

Fig. 4. Liver function tests in mice infused with Ad.CMV.rhHGF or Ad.CMV.lacZ. Serum levels of alanine amino-transferase (ALT) were determined in mice infused with 1 to $4 \times 10^{11}$ particles of Ad.CMV.rhHGF or Ad.CMV.lacz.

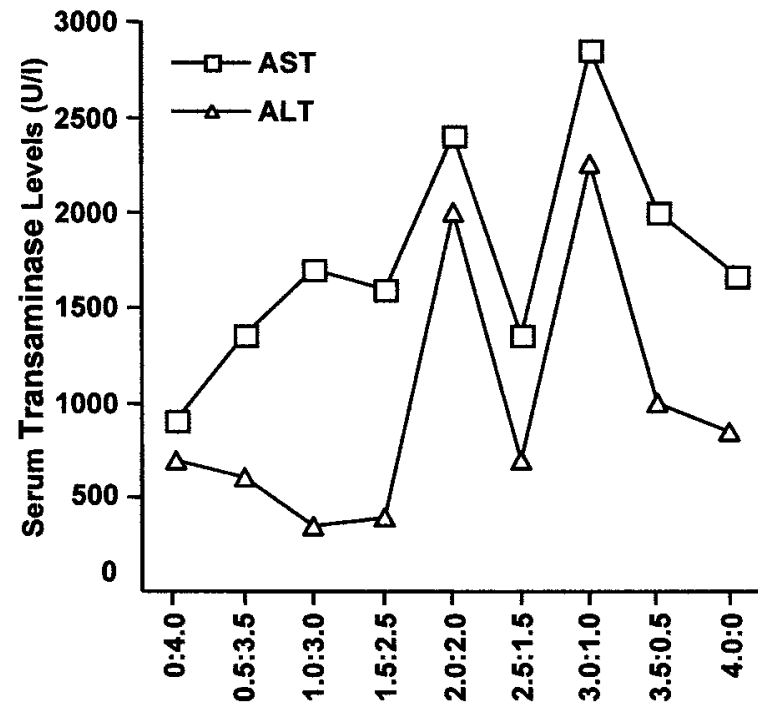

Fig. 5. Liver function tests in mice infused with both vectors at different ratios. Serum transaminase (ALT and AST) levels were determined in mice infused with a total of $4 \times 10^{11}$ particles of both vectors (Ad.CMV.rhHGF or

Ad.CMV.lacZ) mixed at different ratios. The ratio of Ad.CMV.lacZ:Ad.CMV.rhHGF $\left(\times 10^{11}\right)$ particles is indicated on the $\mathrm{x}$-axis.

results suggest that rhHGF has a protective effect against adenovirus-induced pathology.

\section{Discussion}

Hepatocyte growth factor was originally isolated as a potent mitogen for mature hepatocytes (21). The mitogenecity of HGF was demonstrated in primary hepatocyte cultures $(4,22)$, in the regenerating liver after partial hepatectomy (23) or hepatotoxin administration $\left(\mathrm{CCl}_{4}\right.$ or D-galactosamine) (24), and in transgenic mice overexpressing HGF (25). However, attempts to induce liver proliferation in normal, intact animals have proven difficult, leading to the notion that normal hepatocytes are largely unresponsive to growth factors unless they are primed by liver injury (26-28). The inability to induce liver proliferation in intact, normal animals may be explained by the short plasma half-life $(<5 \mathrm{~min})$ of HGF $(29,30)$, suggesting that high doses of HGF may be necessary for maximal HGF activity and liver regeneration. Indeed, high doses of HGF were achieved by a continuous $5 \mathrm{~d}$ infusion of exogenous recombinant human HGF in mature, intact mice that resulted in a $>140 \%$ increase in relative liver mass (14). 


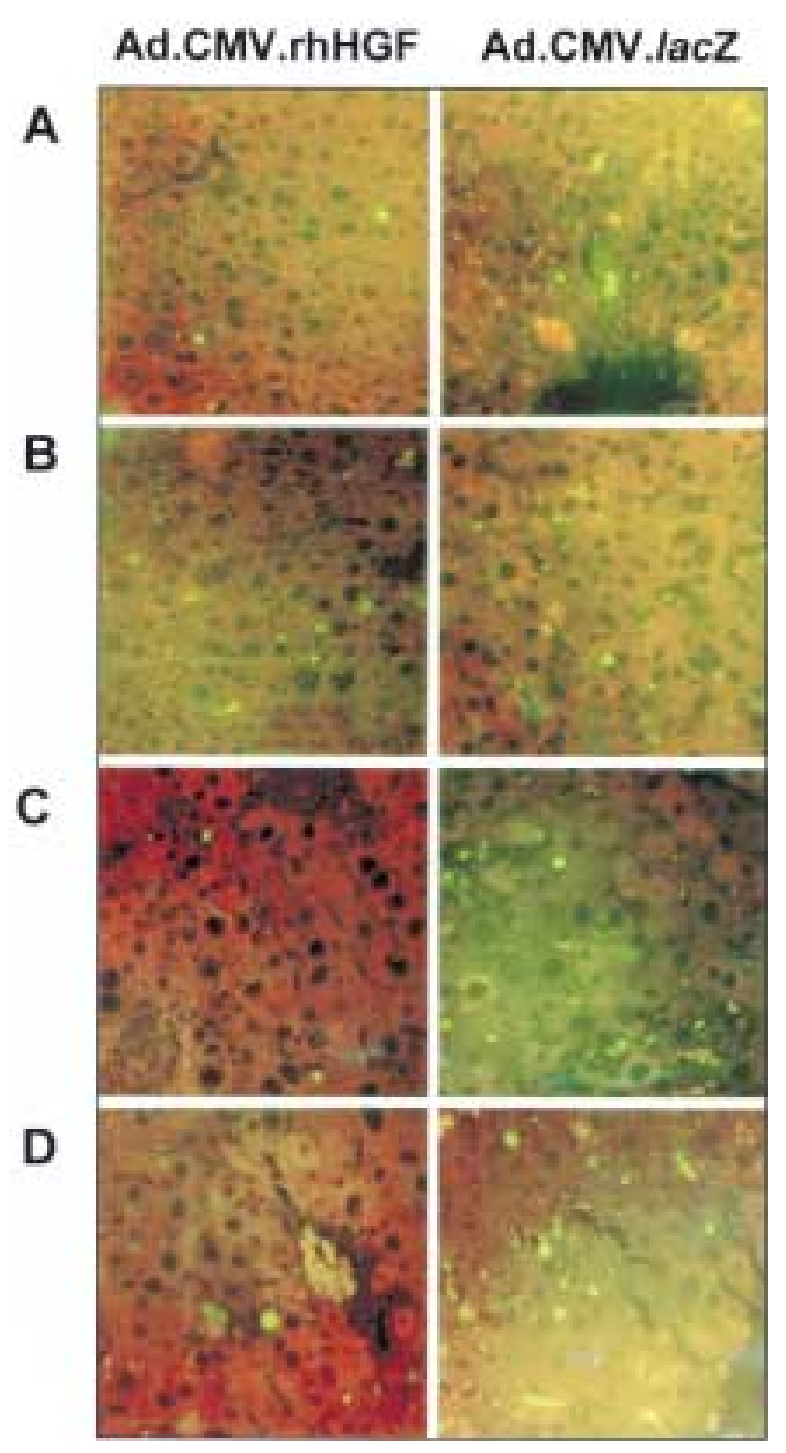

Fig. 6. TUNEL staining (apoptotic cell death) assay on sectioned livers. Mice were injected with (A) $1 \times 10^{11}$, (B) $2 \times 10^{11}$, (C) $3 \times 10^{11}$, or (D) $4 \times 10^{11}$ particles of Ad.CMV.rhHGF or Ad. CMV.lacZ. The incorporation of fluorescein-dUTP was detected microscopically.

In this study, we investigated whether sufficiently high doses of rhHGF could be obtained in normal, intact mice by the administration of an adenoviral vector encoding rhHGF. The intravenous administration of 2 to $4 \times 10^{11}$ particles of Ad.CMV.rhHGF stimulated DNA synthesis and liver growth in normal, intact mice. The maximal effect was seen after the infusion of $3 \times 10^{11}$ particles, which resulted at day 5 in to a $>130 \%$ increase in relative liver mass with little cytopathic effect. Therefore, in vivo DNA synthesis and hepatocyte proliferation in normal mice can be achieved by a single intravenous injection of an adenovirus carrying the rhHGF gene without the need to provoke liver injury or intraportal infusion of exogenous hHGF for an extended period of time, as previously described $(14,31)$.

Interestingly, the control vector (Ad.CMV. lacZ) used in our study caused a certain degree of hepatotoxicity not observed in livers of mice injected with the Ad.CMV.rhHGF. Hepatotoxicity was assessed by measuring serum ALT levels and the presence of apoptotic cells was assessed in the liver by TUNEL staining. Significantly higher levels of serum ALT and liver cell death were observed in mice injected with Ad.CMV.lacz, than in animals infused with Ad.CMV.rhHGF. These findings are consistent with the observed protective effect of HGF on $\mathrm{CCl}_{4}$ - and lipopolysaccharide-induced liver injury and hepatitis $(32,33)$. Moreover, hHGF was recently shown to produce the complete resolution of fibrosis in the cirrhotic liver of dimethylnitrosamine-treated rats (34). The antiapoptotic property of hHGF was also documented in mice treated with interferon-gamma and other DNA damaging agents $(35,36)$. Similar HGF-related apoptotic effects were reported in the kidney $(37,38)$.

In conclusion, a single injection of Ad.CMV.rhHGF is sufficient to induce DNA synthesis and hepatocyte replication in livers of normal, intact mice, which should facilitate studies in liver regeneration. As additional proof, during the preparation of this manuscript, Gao et al. (39) reported that the intramuscular injection in normal mice of an adenoviral vector expressing rhHGF resulted in hepatocyte replication with no cytopathic effect in the liver.

\section{Acknowledgments}

Support from the Clinical Pathology Core of the Institute for Human Gene Therapy was appreciated. This work was supported by grants from the NIH (NICHD P01-AD32649-05, NIDDK P30-DK47757-06, and NHLBI P01HL59407-01) and Genovo, Inc., a biotechnology company founded by Dr. Wilson.

\section{References}

1. Matsumoto K, Nakamura N. (1996) Emerging multipotent aspects of hepatocyte growth factor. J Biochem. (Tokyo) 119: 591-600. 
2. Stoker M, Gherardi E, Perryman M, Gray J. (1987) Scatter factor is a fibroblast-derived modulator of epithelial cell mobility. Nature 327: 239-242.

3. Naldini L, Weidner KM, Vigna E, et al. (1991) Scatter factor and hepatocyte growth factor are indistinguishable ligands for the MET receptor. EMBO J. 10: 2867-2878.

4. Nakamura T, Nawa $K$, Ichihara A, Kaise N, Nishino T. (1987) Purification and subunit structure of hepatocyte growth factor from rat platelets. FEBS Lett. 224: 311-316.

5. Rubin JS, Bottaro DP, Aaronson SA. (1993) Hepatocyte growth factor/scatter factor and its receptor, the c-met proto-oncogene product. Biochim. Biophys. Acta. 1155: 357-371.

6. Gohda E, Tsubouchi H, Nakayama $H$, et al. (1988) Purification and partial characterization of hepatocyte growth factor from plasma of a patient with fulminant hepatic failure. J. Clin. Invest. 81: 414-419.

7. Asami O, Ihara I, Shimidzu N, Shimizu S, Tomita Y, Ichihara A, Nakamura T. (1991) Purification and characterization of hepatocyte growth factor from injured liver of carbon tetrachloridetreated rats. J. Biochem. (Tokyo) 109: 8-13.

8. Selden C, Johnstone R, Darby H, Gupta S, Hodgson HJ. (1986) Human serum does contain a high molecular weight hepatocyte growth factor: studies pre- and post-hepatic resection. Biochem. Biophys. Res. Commun. 139: 361-366.

9. Nakamura T, Nishizawa $T$, Hagiya $M$, et al. (1989) Molecular cloning and expression of human hepatocyte growth factor. Nature 342: 440-443.

10. Miyazawa K, Tsubouchi H, Naka D, et al. (1989) Molecular cloning and sequence analysis of cDNA for human hepatocyte growth factor. Biochem. Biophys. Res. Commun. 163: 967-973.

11. Tashiro K, Hagiya M, Nishizawa T, et al. (1990) Deduced primary structure of rat hepatocyte growth factor and expression of the mRNA in rat tissues. Proc. Natl. Acad. Sci. U.S.A. 87: 32003204.

12. Okajima A, Miyazawa K, Kitamura N. (1990) Primary structure of rat hepatocyte growth factor and induction of its mRNA during liver regeneration following hepatic injury. Eur. J. Biochem. 193: 375-381.

13. Liu Y, Michalopoulos GK, Zarnegar R. (1993) Molecular cloning and characterization of cDNA encoding mouse hepatocyte growth factor. Biochim. Biophys. Acta. 1216: 299-303.

14. Patijn GA, Lieber A, Schowalter DB, Schwall R, Kay MA. (1998) Hepatocyte growth factor induces hepatocyte proliferation in vivo and allows for efficient retroviral-mediated gene transfer in mice. Hepatology 28: 707-716.

15. Liu M-L, Mars WM, Zarnegar R, Michalopoulos GK. (1994) Collagenase pretreatment and the mitogenic effects of hepatocyte growth factor and transforming growth factor- $\alpha$ in adult rat liver. Hepatology 19: 1521-1527.

16. Ye X, Robinson MB, Batshaw ML, Furth EE, Smith I, Wilson JM. (1996) Prolonged metabolic correction in adult ornithine transcarbamylase-deficient mice with adenoviral vectors. J. Biol. Chem. 1996 271: 3639-3646.

17. Kozarsky KF, McKinley DR, Austin LL, Raper SE, Stratford-Perricaudet LD, Wilson JM. (1994) In vivo correction of low density lipoprotein receptor deficiency in the Watanabe heritable hyperlipidemic rabbit with recombinant adenoviruses. J. Biol. Chem. 269: 13695-13702.

18. Yang Y, Ertl HC, Wilson JM. (1994) MHC class I-restricted cytotoxic $\mathrm{T}$ lymphocytes to viral antigens destroy hepatocytes in mice infected with El-deleted recombinant adenoviruses. Immunity 1: 433-442.

19. Yang Y, Nunes FA, Berencsi K, Furth EE, Gonczol E, Wilson JM. (1994) Cellular immunity to viral antigens limits El-deleted adenoviruses for gene therapy. Proc. Natl. Acad. Sci. U.S.A. 91: 4407-4411.

20. Jooss K, Yang Y, Wilson JM. (1996). Cyclophosphamide diminishes inflammation and prolongs transgene expression following delivery of adenoviral vectors to mouse liver and lung. Hum. Gene Ther. 7: 1555-1566.

21. Zarnegar R, Michalopoulos G. (1989) Purification and biological characterization of human hepatopoietin A, a polypeptide growth factor for hepatocytes. Cancer Res. 49: 3314-3320.

22. Nakamura T, Nawa K, Ichihara A. (1984) Partial purification and characterization of hepatocyte growth factor from serum of hepatectomized rats. Biochem. Biophys. Res. Commun. 122: 14501459.

23. Lindroos PM, Zarnegar R, Michalopoulos GK. (1991) Hepatocyte growth factor (hepatopoietin A) rapidly increases in plasma before DNA synthesis and liver regeneration stimulated by partial hepatectomy and carbon tetrachloride administration. Hepatology 13: 743-750.

24. Kinoshita T, Tashiro K, Nakamura T. (1989) Marked increase of HGF mRNA in nonparenchymal liver cells of rats treated with hepatotoxins. Biochem. Biophys. Res. Commun. 165: 1229-1234.

25. Shiota G, Wang TC, Nakamura T, Schmidt EV. (1994) Hepatocyte growth factor in transgenic mice: effects on hepatocyte growth, liver regeneration and gene expression. Hepatology 19: 962-972.

26. Webber EM, Godowski PJ, Fausto N. (1994) In vivo response of hepatocytes to growth factors requires an initial priming stimulus. Hepatology 19: 489-497.

27. Ishii T, Sato M, Sudo K, et al. (1995) Hepatocyte growth factor stimulates liver regeneration and 
elevates blood protein level in normal and partially hepatectomized rats. J. Biochem. (Tokyo) 117: 1105-1112.

28. Fujiwara K, Nagoshi S, Ohno A, et al. (1993) Stimulation of liver growth by exogenous human hepatocyte growth factor in normal and partially hepatectomized rats. Hepatology 18: 1443-1449.

29. Zioncheck TF, Richardson L, DeGuzman GG, Modi NB, Hansen SE, Godowski PJ. (1994) The pharmacokinetics, tissue localization, and metabolic processing of recombinant human hepatocyte growth factor after intravenous administration in rats. Endocrinology 134: 1879-1887.

30. Liu KX, Kato Y, Narukawa M, et al. (1992). Importance of the liver in plasma clearance of hepatocyte growth factors in rats. Am. J. Physiol. 263: G642-G649.

31. Kobayashi Y, Hamanoue $M$, Ueno $S$, et al. (1996) Induction of hepatocyte growth by intraportal infusion of HGF into beagle dogs. Biochem. Biophys. Res. Commun. 220: 7-12.

32. Kaido T, Yamaoka S, Tanaka J, et al. (1996) Continuous HGF supply from HGF-expressing fibroblasts transplanted into spleen prevents CCl4-induced acute liver injury in rats. Biochem. Biophys. Res. Commun. 218: 1-5.

33. Kaido T, Yamaoka S, Seto S, et al. (1997) Continuous hepatocyte growth factor supply pre- vents lipopolysaccharide-induced liver injury in rats. FEBS Lett. 411: 378-382.

34. Ueki T, Kaneda Y, Tsutsui H, et al. (1999) Hepatocyte growth factor gene therapy of liver cirrhosis in rats. Nat. Med. 5: 226-230.

35. Fan S, Wang JA, Yuan RQ, Rockwell S, Andres J, Zlatapolskiy A, Goldberg ID, Rosen EM. (1998) Scatter factor protects epithelial and carcinoma cells against apoptosis in-duced by DNA-damaging agents. Oncogene 17: 131-141.

36. Morita M, Watanabe Y, Akaike T. (1995) Protective effect of hepatocyte growth factor on interferon-gamma-induced cytotoxicity in mouse hepatocytes. Hepatology 21: 1585-1593.

37. Yo Y, Morishita R, Nakamura S, et al. (1998) Potential role of hepatocyte growth factor in the maintenance of renal structure: anti-apoptotic action of HGF on epithelial cells. Kidney Int. 54: 1128-1138.

38. Liu Y, Sun AM, Dworkin LD. (1998) Hepatocyte growth factor protects renal epithelial cells from apoptotic cell death. Biochem. Biophys. Res. Commun. 246: 821-826.

39. Gao C, Jokerst R, Gondipalli P, Cai SR, Kennedy S, Ponder KP. (1999) Intramuscular injection of an adenoviral vector expressing hepatocyte growth factor facilitates hepatic transduction with a retroviral vector in mice. Hum. Gene Ther. 10: 911-922. 